\title{
Generator with modulated magnetic flux for wind turbines
}

\author{
M. GWÓŹDŹ*, M. KRYSTKOWIAK, C. JĘDRYCZKA, A. GULCZYŃSKI, and D. MATECKI \\ Institute of Electrical Engineering and Electronics, Poznań University of Technology, 3A Piotrowo St., 60-965 Poznań, Poland
}

\begin{abstract}
In the paper, the concept of a permanent magnet synchronous generator (PMSG) with uniquely designed stator windings for wind turbines is presented. Two 3-phase windings in the stator are used, one of which is connected in the star, while the other in the delta configuration. Six-pulse rectifiers, mutually coupled by the pulse transformer, whose primary winding is supplied by the so-called "current modulator", are placed at the outputs of both windings. The modulator output current should meet all the necessary and strict requirements. Both rectifiers operate on a common DC circuit. These solutions provide the sinusoidal magnetomotive force in the stator of the PMSG and the quasi-sinusoidal (taking into account the non-linearity of the magnetic circuit) magnetic flux. In light of the generator principle, it has been called the "PMSG with modulated the magnetic flux". The slightly higher complexity in the structure of the generator, as compared to the normal threephase construction, is compensated by the exceptional simplicity of the power electronics section of the system, which allows high efficiency to be reached. The current modulator (as well as the pulse transformer) is a power electronics converter with a relatively low output power as compared to the overall output power of the system. In comparison to other known solutions, the expected cost of the system should be lower. It is also expected that a high degree of reliability in terms of its operation will be achieved, and consequently, that the the ongoing costs of its maintenance will be reduced. In the paper, concept, theoretical basis of operation, and results of the studies of the simulation models of the generator, including the basic power electronics section, are presented.
\end{abstract}

Key words: current modulator, PMSG, power electronics converter, renewable energy source, wind turbine.

\section{Introduction}

Wind power has emerged as one of the most dominant sources of renewable energy with an immense growth potential across the globe. According to Global Wind Energy Council [1], 2015 was an unprecedented year for the wind industry, as annual installations crossed the $60 \mathrm{GW}$ mark for the first time in history, and more than $63 \mathrm{GW}$ of new wind power capacity was brought on line. The last record was set in 2014, when over $51 \mathrm{GW}$ of new capacity were installed globally. The new global total for wind power at the end of 2015 was $432 \mathrm{GW}$, representing a cumulative market growth of more than $17 \%$.

The variable nature of wind energy sources (in terms of real power, reactive power, output voltage, and frequency) is a major issue. Various power conversion systems have been developed to fulfill the requirements of wind power generation. In this chapter, a brief review of the most commonly used state-ofthe-art generators is presented, emphasizing their advantages and vice versa.

The main types of generators used in renewable sources of energy (RES) are AC poly-phase machines. There are two major types: induction and synchronous. They vary by principle of operation, construction, size, application, and generated power. This section looks closely at two types of induction generators: squirrel-cage and doubly-fed, as well as three types of synchronous generators: electrically excited, permanent magnet, and high-temperature-superconducting.

*e-mail: michal.gwozdz@put.poznan.pl

Manuscript submitted 2016-11-03, revised 2016-12-22, initially accepted for publication 2017-01-23, published in August 2017.
1.1. Induction generators. A squirrel cage induction generator (SCIG) is the most popular generator type of fixed-speed stall control wind turbines [2]. The advantages of this type of generator are that it is inexpensive to mass produce, that it is made with robust and easy technology, and that it has a direct connection to the grid [2-4]. The disadvantages are: a limited range variation of speed, which is not controllable, and a multiple-stage gearbox. It also always consumes reactive power which is not controllable [4].

The following popular solution for RES is a doubly-fed induction generator (DFIG). The introduction of DFIGs was dictated by the demand for an increase in the level of power capture, the grid requirement for good power quality, as well as a reduction of the noise level and mechanical stress of the drivetrain [5]. The operation principle between a DFIG and a SCIG is the same, but a DFIG rotor has a three-phase winding instead of a squirrel-cage rotor like in the SCIG. The DFIG's advantage over a SCIG is controllable reactive power. It is achieved through the rotor current in the converter. Sufficient range of variable speed and control over power flow direction also cannot be neglected [3]. Brushes and the multiple-stage gearbox, which require regular maintenance, can be a potential cause of machine failure. Because of the connection to the grid leading through expensive power electronic converters that are very sensitive to overcurrents, protection from grid disturbances is very complex [5-7].

1.2. Synchronous generator (SG). Nowadays, SGs have become competitive for induction generators in terms of design [8-12]. Different designs of SGs have been developed, for example: DC-current-excited rotors, claw-pole electrically-excited 
rotors, permanent magnet rotors, and variable reluctance rotors [4]. Low speed and high torque SGs are called direct drive (DD) generators. In this solution, the rotor of a DD generator is directly connected to the hub of the rotor blades [4]. In comparison to a regular generator connected to a gearbox system, a DD generator rotates at a lower rotational speed. As a result, there is a need to produce a higher level of torque. The lack of a gearbox causes a DD machine with a large number of poles to control the generator speed over a wide range. The consequence of a larger number of poles is a generator heavier and larger in diameter. The advantages of this solution are lower manufacturing cost, lower generated noise, and less pollution. Regular maintenance because of risk of mechanical failure of the gearbox is eliminated [12-19]. The disadvantage is a higher start-up cost.

\subsection{Electrically excited synchronous generator (EESG).} The EESG (or wound-field SG) stator is the same as that of the induction machine carrying a three-phase winding. Its rotor may have salient or cylindrical poles [20]. The amplitude and frequency of the voltage on the generator side of an EESG converter can be fully controlled by the converter, independently of the grid characteristics [3]. In comparison with a permanent magnet synchronous generator, an EESG does not require permanent magnets (PMs), which causes a cost reduction. DFIGs are made of low-cost steel parts, which keep the installation costs low, but require the low-cost parts to be switched out often to maintain reliability. The necessity of exciting its rotor winding by a DC current source using brushes and slip rings or a rotating rectifier without using brushes is the main drawback. Other drawbacks include the use of expensive power electronic components and the requirement of intensive cooling.

\subsection{Permanent magnet synchronous generator (PMSG). The} rotor in a permanent magnet synchronous generator is equipped with permanent magnets. Thus, the excitation is provided by PMs instead of the field winding, but the stator winding is the same as that of a three-phase EESG [18]. The advantages over EESGs are: smaller rotor diameters, higher reliability due to elimination of different mechanical components, better thermal characteristics, and lower mass per kilowatt of output power [21-24]. The disadvantage is that PMSGs need more robust control strategies, in order to maintain transient stability and avoid the risk of wind turbine mechanical runaway during faulty conditions [21]. The PM generators are recognized as being the most efficient choice among the current generator designs on the market. They make the most economic sense due to their high efficiency, as well as due to their low maintenance and part replacement costs over the lifetime of a wind turbine. This is despite the fact that they require a higher initial material cost as compared to DFIGs, which is the reason for PMs not being the dominant generator topology. PM generators mostly use magnets that are more expensive than the steel parts of DFIGs, but have a higher reliability because of having fewer moving parts. Unconventional, e.g. multiphase PMSGs, are considered [35]. Moreover, the new $42 \mathrm{~V}$ system proposed for future cars will also be powered by means of permanent magnet alternators [36].
1.5. High-temperature superconducting synchronous generator (HTS-SG). High- temperature superconducting synchronous generator (HTS-SG) machines consist of a combination of bulk HTS material and wires [25-29]. HTS windings can operate at a very high temperature and can be cooled with low cost and reliable off-the-shelf refrigerators [26, 27]. Thus, HTS wires provide higher current densities (up to $200 \mathrm{~A} / \mathrm{mm}^{2}$ compared with about $5 \mathrm{~A} / \mathrm{mm}^{2}$ in EESGs [21], reducing the space required for the rotor field winding [21, 24-27]. The possibility of placing more turns of field winding in a small volume also allows for an increase of the air-gap flux density, consequently making it possible to increase the air-gap, resulting in weight reduction and less stress. HTS generators, in comparison with PMSGs and EESGs, are more efficient, lighter, and more compact, while being more affordable and robust in design [20-22, 24-31, 37].

Taking into account the pros and cons of the aforementioned power systems for RES in the paper, the novelty concept of PMSG, coupled with a specific power electronics converter is considered. The system has most of the advantages of the existing solutions of power systems for RES, whereas its complexity is lower. So, it is expected that it will be both cost-competitive and more reliable, compared to other known power systems.

The following part of the paper is divided into four sections. The first one deals with the structure of the power system based on the proposed generator and rules of its operation. The second part presents the research of simulation models for both the proposed power system and the so-called "standard model" of the system. The third part presents the first stage of the experimental studies. In the last part, the conclusions are presented.

\section{Power system background}

The basis of the system is the uniquely designed PMSG coupled to a wind turbine, which would allow, together with a dedicated power electronics converter, to return the produced energy to the grid or to be use it locally, depending on the current need.

The main objective of the system is to provide a high efficiency (effectiveness) of the conversion of mechanical energy into electricity by the simple means of an electrical system. This effect gives the generator with uniquely designed stator windings and a special power electronics converter an ability to enforce a sinusoidal magnetomotive force $(\mathrm{mm} f)$. A consequence of this is that the resultant magnetic flux is close to the sine wave. This allows to limit the power loss in "iron", which, in addition to the loss in "copper", is one of the major power losses in the machine. In this case, the power electronics converter connecting the generator to the load has a simplified design, which mostly uses the uncontrolled rectifiers, providing the high energy conversion efficiency. This solution is mainly dedicated to medium- and large-capacity systems, where the advantages are particularly visible. The block diagram of the basic part of the system is shown in Fig. 1. However, the power electronics section connecting the base part of the system with the power grid is not of concern to this paper. 


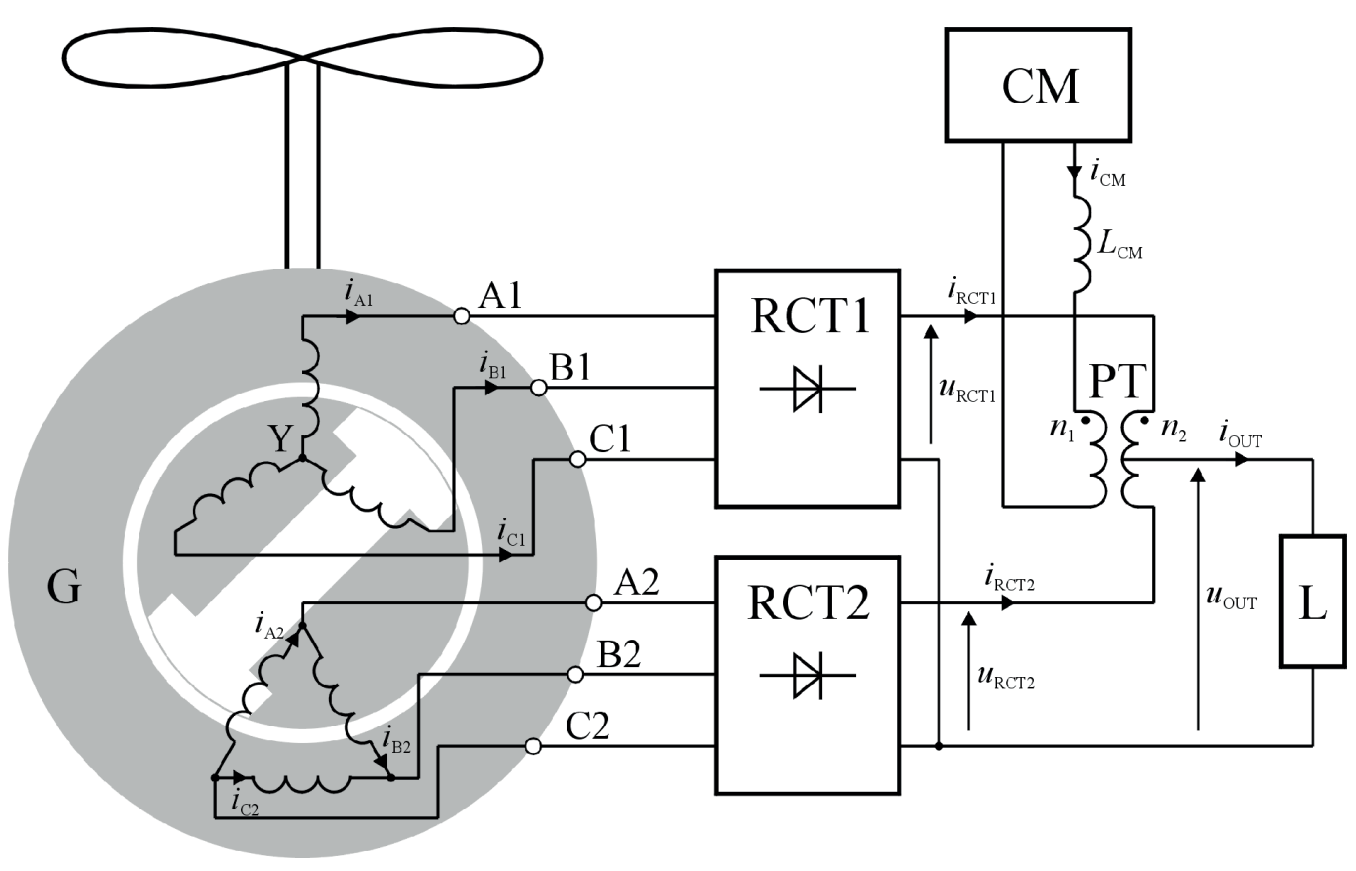

Fig. 1. Block scheme of the power conversion system

The electrical energy source is a PMSG $(G)$ with unconventional construction of the stator windings. There is a pair of three-phase windings in the stator, one of them is connected in the star, while the other is connected in the delta configuration. This solution is necessary to obtain the desired effect of the machine operation, as mentioned earlier. Voltages at the terminals of the machine (windings) should have the same value. Both windings are burdened by independent 6-pulse diode rectifiers (RCT1, RCT2). The power electronics converter, called the "current modulator" (CM), is located at the outputs of both rectifiers, shaping their output currents $\left(i_{\mathrm{RCT} 1}, i_{\mathrm{RCT} 2}\right)$. The CM generates the output current $\left(i_{\mathrm{CM}}\right)$, whose characteristic is defined later. This current flows through the primary winding of the pulse transformer (PT) with a divided secondary winding. The secondary winding of the PT interconnects the outputs of both rectifiers, which means that changing the shape of the rectifiers' output currents is possible by applying the CM output current flowing through the PT.

The relationship between the rectifier's output currents, the modulator's current, and the system's output $\left(i_{\text {OUT }}\right)$ is as follows [32]:

$$
\begin{gathered}
\left(i_{\mathrm{RCT} 2}-i_{\mathrm{RCT} 1}\right) n_{2}=i_{\mathrm{CM}} n_{1}, \\
i_{\mathrm{RCT} 1}=\frac{1}{2}\left(i_{\mathrm{OUT}}-N i_{\mathrm{CM}}\right), \\
i_{\mathrm{RCT} 2}=\frac{1}{2}\left(i_{\mathrm{OUT}}+N i_{\mathrm{CM}}\right),
\end{gathered}
$$

where: $n_{1}, n_{2}$ are the PT winding turns, and $N=\frac{n_{1}}{n_{2}}$.

The primary objective of the current modulator with a pulse transformer is to ensure the proper shape of the phase currents of the generator $(\mathrm{G})$, so that the resultant $m m f$ associated with a given pair of windings (star-delta) is a sine wave, which enables to minimize power losses in its magnetic circuit. This phenomenon has been called "the modulation of the magnetic flux", which refers directly to the principles of the CM operation. In order to ensure the sine shape of the $m m f$, the CM output current must comply with the following equation [32]:

$$
\begin{aligned}
i_{\mathrm{CM}}(t) & =\frac{\frac{6}{\pi} I_{\mathrm{OUT}} \cos \left(\omega_{\mathrm{G}} t\right)}{-\cos \left(6 k \omega_{\mathrm{G}} t\right)+\cos \left(6 k \omega_{\mathrm{G}} t+\frac{\pi}{6}\right)} \frac{1}{N} \\
& -\frac{I_{\mathrm{OUT}}\left[\cos \left(6 k \omega_{\mathrm{G}} t\right)+\cos \left(6 k \omega_{\mathrm{G}} t+\frac{\pi}{6}\right)\right]}{-\cos \left(6 k \omega_{\mathrm{G}} t\right)+\cos \left(6 k \omega_{\mathrm{G}} t+\frac{\pi}{6}\right)} \frac{1}{N}, \\
& : k=0,1,2, \ldots
\end{aligned}
$$

where $\omega_{\mathrm{G}}$ is the frequency of the generators' output voltage. It is also possible to use the simplified and more comfortable form of (4):

$$
\begin{aligned}
i_{\mathrm{CM}}(t) & =\frac{4}{\pi} I_{\mathrm{OUT}} \sin \left(6 \omega_{\mathrm{G}} t\right) \frac{1}{N}+ \\
& -\frac{4}{\pi} I_{\mathrm{OUT}}\left[\frac{\sin \left(36 \omega_{\mathrm{G}} t\right)}{3^{2}}+\frac{\sin \left(56 \omega_{\mathrm{G}} t\right)}{5^{2}}-\ldots\right] \frac{1}{N} .
\end{aligned}
$$

The CM current given by (5) has a triangular shape, of which the fundamental frequency is 6 times higher than the current value of $\omega_{\mathrm{G}}$. Using (5) instead of (4) results in only a small increase in the deformation of the PMSG $m m f$, with respect to the desired sinusoidal shape. 
(a)

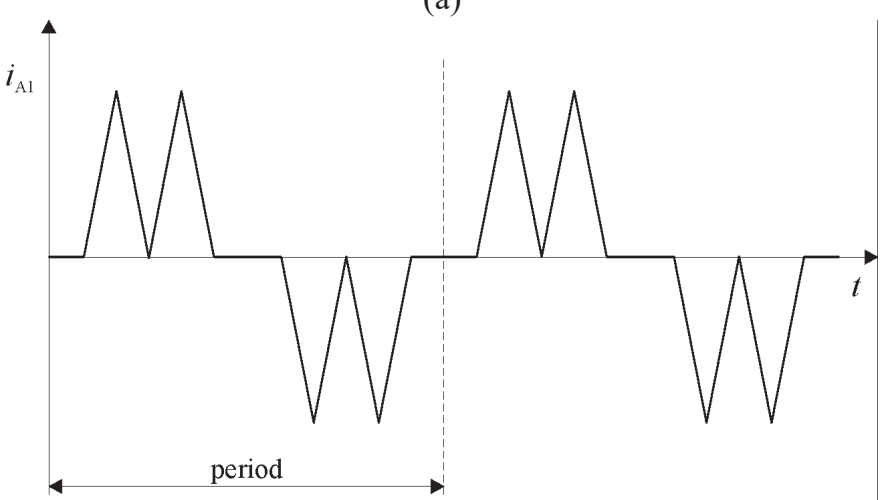

(b)

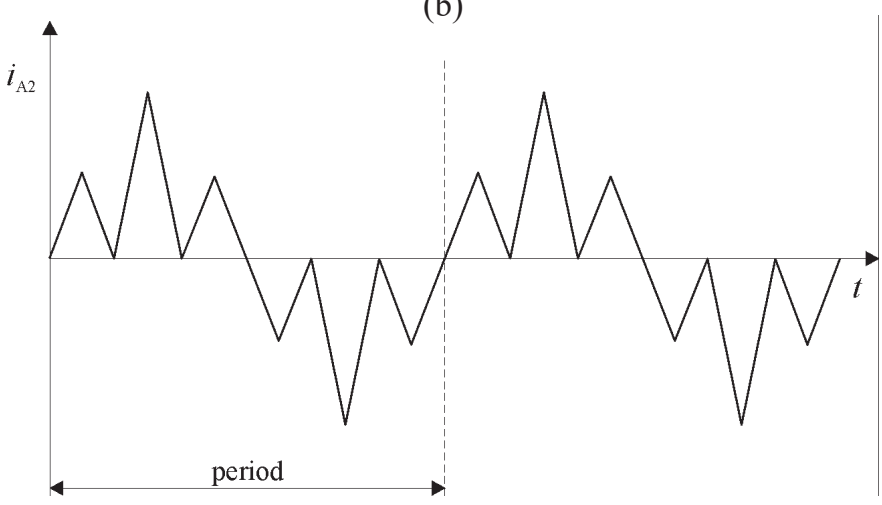

Fig. 2. Theoretical shape of the phase current of the generator (single phase) for a group of connections: a) star, b) delta

Taking into account (5), the expected shape of the phase currents of the generator (i.e. $i_{\mathrm{A} 1}$ etc. and $i_{\mathrm{A} 2}$ etc.) will look as shown in Fig. 2. From the point of view of performance and complexity of the systems' construction, one of its very important features is that the power of both the current modulator and the pulse transformer is very low in relation to the total power output of the system.

As a result, the $m m f$ associated with each pair of stator windings is quasi-sinusoidal (Fig. 3).

It is an important assumption for the expected operation of the current shaping circuit (i.e. CM) that the system's total

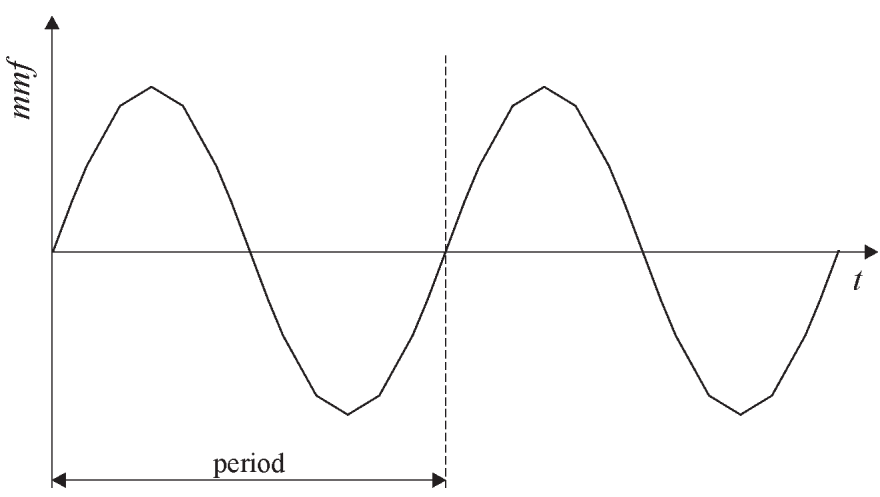

Fig. 3. Resultant $m m f$ associated with a pair of windings - the first one is connected in the star, and the second in the delta configuration output current $\left(i_{\text {OUT }}\right)$ over time is constant. Hence, it is necessary to automatically (based on the dedicated control algorithm) adjust its value, by means of parameter $I_{\text {OUT }}$ of (4) and (5). The value of this parameter should be associated with the changes of the output power of the generator caused by e.g. a change in the speed of the wind. This requirement imposes the design of voltage and current transducers being located at the output of the real energy's conversion system.

\section{Simulation studies}

The main aim of the study was to compare the efficiency of the energy conversion system based on the proposed generator (MNS - model of the novelty system) in relation to the standard energy conversion system (MSS - model of the standard system). The MSS was a conventional 3-phase PMSG with a full-rating power converter. This power converter was an active (IGBT-based) rectifier providing sinusoidal waveforms of the generator phase currents. This type of standard model was selected due to both its similarity to the proposed PMSG and its huge popularity in power systems based on renewable energy [33]. The rated output power of both models was very similar and equal to approximately $5.4 \mathrm{~kW}$.

3.1. Model of the generator. In order to assess the performance of the proposed PMSG with star-delta winding, a comparative analysis using the finite element method (FEM) has been performed. The torque constant and core losses have been compared with a conventionally-designed (standard) PMSG supplied by a balanced sinusoidal 3-phase system of winding currents. Two FEM models of PMSGs have been developed in the Ansys Maxwell environment. The geometry of the magnetic circuits of both models is the same (permanent magnet size, air-gap length, teeth/slot dimensions). The only difference between the models is in the winding design. The machine discussed in the paper consists of two independent windings arranged in star and delta configurations. The particular coils are placed in the same slots, while number of turns in star- and delta-arranged coils are set to produce the same values of line-to-line electromotive force. A low-speed test machine of 44 poles and 48 slots with a 3-phase double-layer fractional-slot concentrated winding has been considered as the problem of the case study. The test machines have been modeled assuming a planar symmetry of the magnetic field distribution along the axial direction. The impact of the end effects on the performance of the machines has been neglected. For comparison purposes, simulation parameters, including mesh density, time step size and tolerance of the Newton-Raphson procedure, have been kept the same when testing the models. The major dimensions and design parameters of the test machine have been summarized in Table 1. A view of the cross-section of the magnetic circuit of the test machine is shown in Fig. 4.

The number of turns of the windings arranged in star and in delta configurations have been selected to give approximately the same values of the open-circuit electromotive force (emf). The calculated back emf waveforms of line-to-line $\left(E_{\mathrm{ab}}\right)$ for 
Table 1

Summary of test generator main pararameters

\begin{tabular}{|l|c|c|}
\hline Parameter & Unit & value \\
\hline Number of slots & {$[-]$} & 48 \\
\hline Number of poles & {$[-]$} & 44 \\
\hline Rated speed & {$[\mathrm{rpm}]$} & 240 \\
\hline Rated torque & {$[\mathrm{Nm}]$} & 180 \\
\hline Rated frequency & {$[\mathrm{Hz}]$} & 88 \\
\hline Rated current & {$[\mathrm{A}]$} & 6.7 \\
\hline Stack length & {$[\mathrm{mm}]$} & 50 \\
\hline Stator outer diameter & {$[\mathrm{mm}]$} & 292 \\
\hline Air-gap & {$[\mathrm{mm}]$} & 1.5 \\
\hline Number of turns (star/delta) & {$[-]$} & $54 / 93$ \\
\hline
\end{tabular}

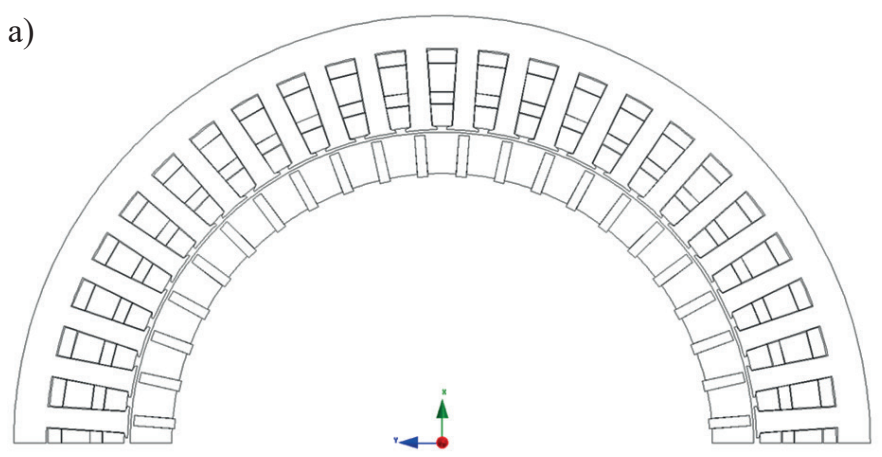

b)

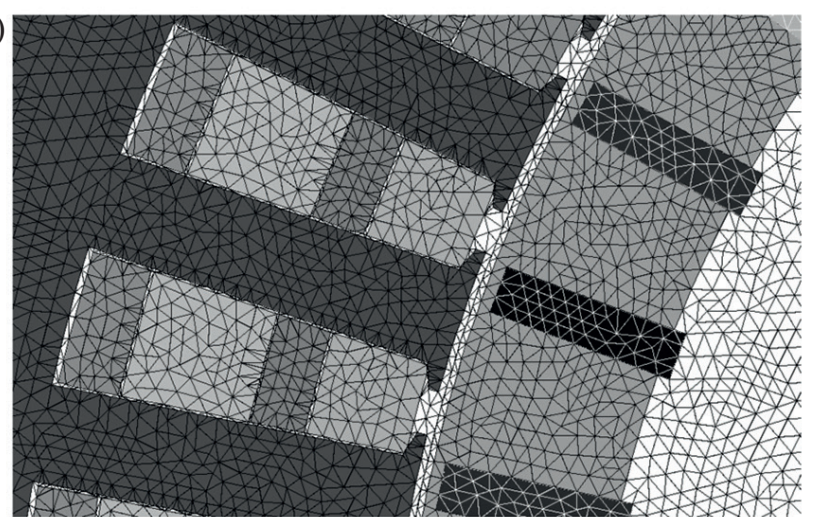

Fig. 4. a) structure of the magnetic circuit of the test machine; b) fragment of the applied finite element mesh

the star winding and phase $\left(E_{\mathrm{a}}\right)$ for delta winding are shown in Fig. 5a, while the line-to-line waveforms of a model with a standard design are shown in Fig. 5b.

The proposed supply system has been implemented in the Ansys MaxCir environment. A schematic of the supply system is shown in Fig. 3. The supply systems of the star and delta windings have been connected by balancing resistance $R_{\mathrm{b}}$ equal to $1 \mathrm{M} \Omega$. Piecewise linear current sources have been used to a)

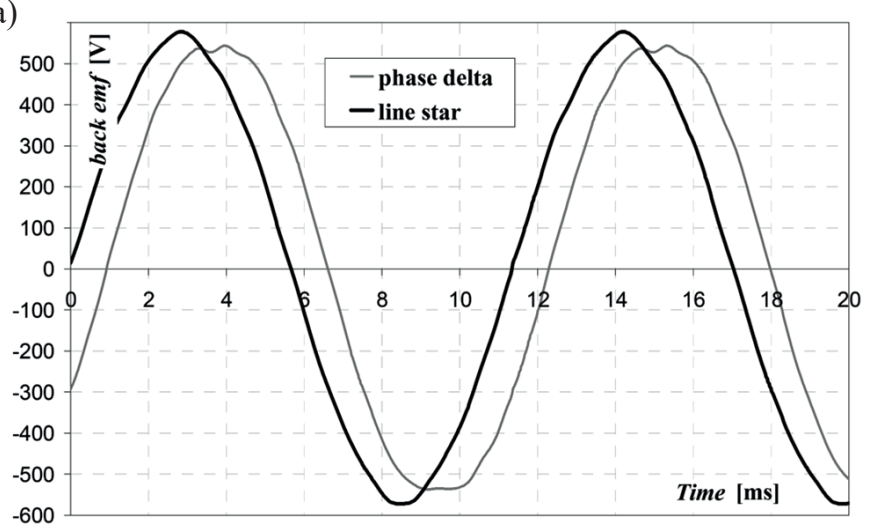

b) - phase $\mathrm{AB} \quad$-o-phase BC - phase $\mathrm{CA}$

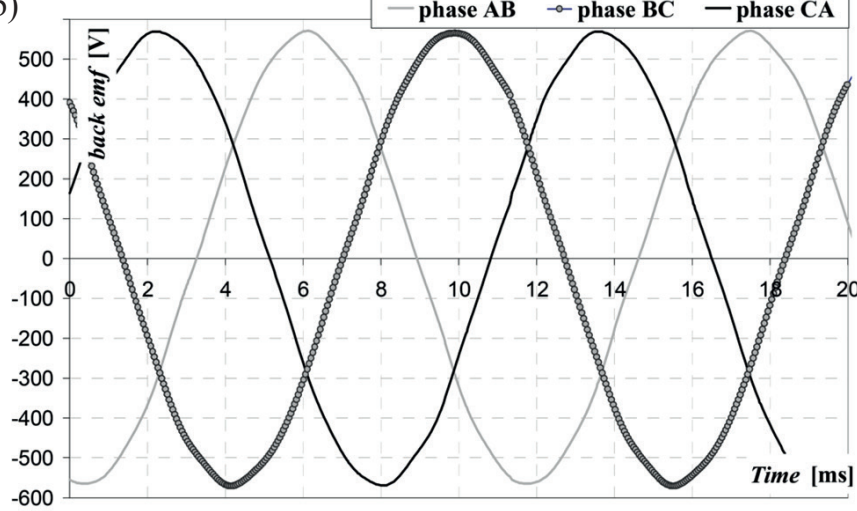

Fig. 5. Back emf waveforms a) phase $E_{\mathrm{a}}$ delta winding and line-to-line $E_{\mathrm{ab}}$ star winding; b) waveforms of $E_{\mathrm{ab}}, E_{\mathrm{bc}}$, and $E_{\mathrm{ca}}$ in a standard machine

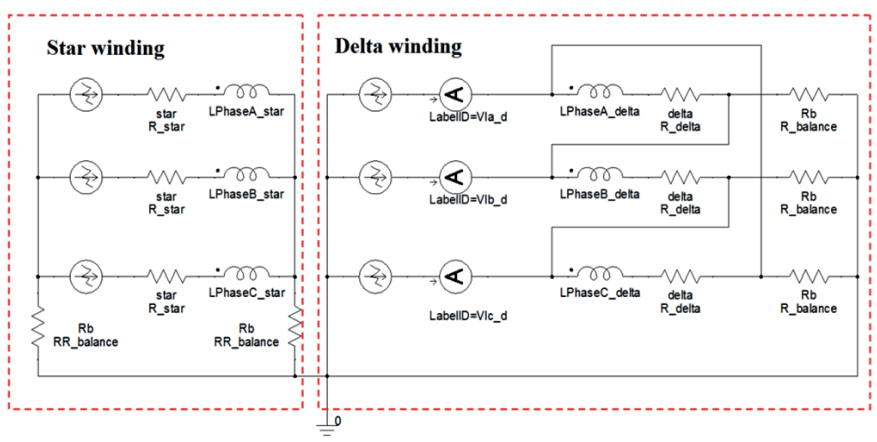

Fig. 6. Electrical scheme of the supply system model

represent the current waveforms of the discussed power electronic system.

The calculated waveforms of the phase currents in the delta and star windings are shown in Figs. $7 \mathrm{a}$ and $7 \mathrm{~b}$, respectively.

Due to a different number of turns in coils of star and delta windings, the slot equivalent current $i_{\mathrm{eq}}$ has been calculated. The value of the equivalent current has been referenced to the total $m m f$ in the slot generated by particular phase windings according to following equation:

$$
i_{\text {eq }}=\frac{N_{\text {star }} i_{\text {star }}+N_{\text {delta }} i_{\text {delta }}}{N_{\text {star }}+N_{\text {delta }}},
$$


a)

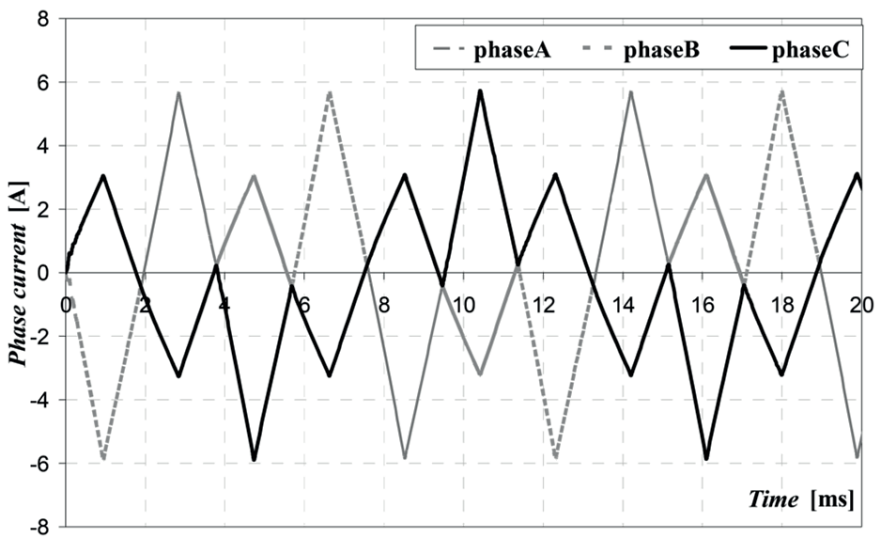

b)

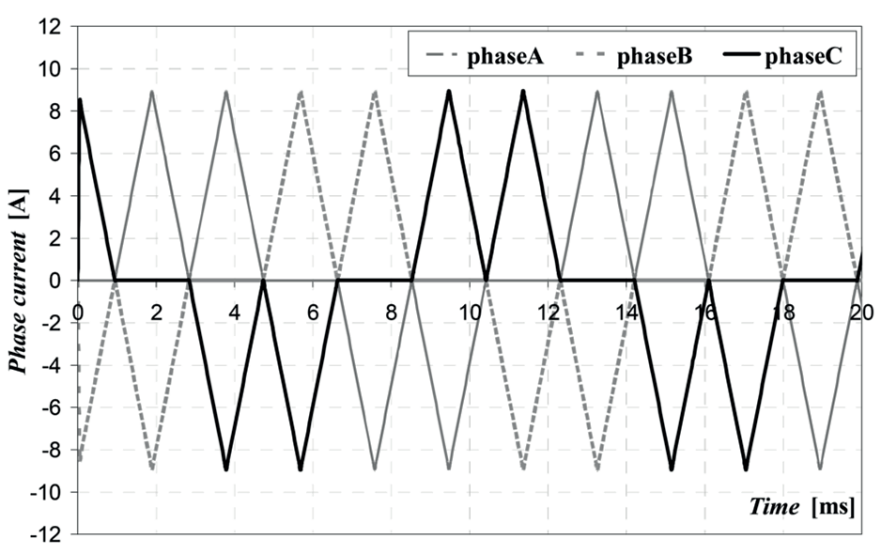

Fig. 7. Phase current waveforms a) delta; b) star winding

It is important to notice that the delta winding forms a closed-loop circuit, and thus, if induced in the phase coils the electromotive forces will contain the common phase harmonics of the electromotive force, the phase current will contain a circulating component. In general, it can be stated that the circulating current will depend on the design of the machine (proper shaping of the magnetic field induced by the permanent magnets) and on the armature reaction field. In other words, to minimize the value of the circulating current, the magnetic circuit of the machine should be designed properly. Nevertheless, due to the armature reaction field, the phase currents in the delta arranged winding (and also equivalent currents $i_{\mathrm{eq}}$ ) will depend on the torque angle of the machine, understood as the electrical angle between the rotor and stator field axes. The calculated waveform of equivalent current $i_{\mathrm{eq}}$ for $a=a_{\max }$ (i.e. the iteratively calculated value of $a$, for which the highest value of electromagnetic torque is obtained for a given value of the supply current) has been shown in Fig. 8a. To analyze the distortion of the obtained equivalent current waveform, the fast Fourier transform (FFT) has been applied. The harmonic content from the equivalent current waveform has been given in Fig. 8 b.

In the next step, the electromagnetic torque waveforms, torque vs. current, and core losses vs. current characteristics a)

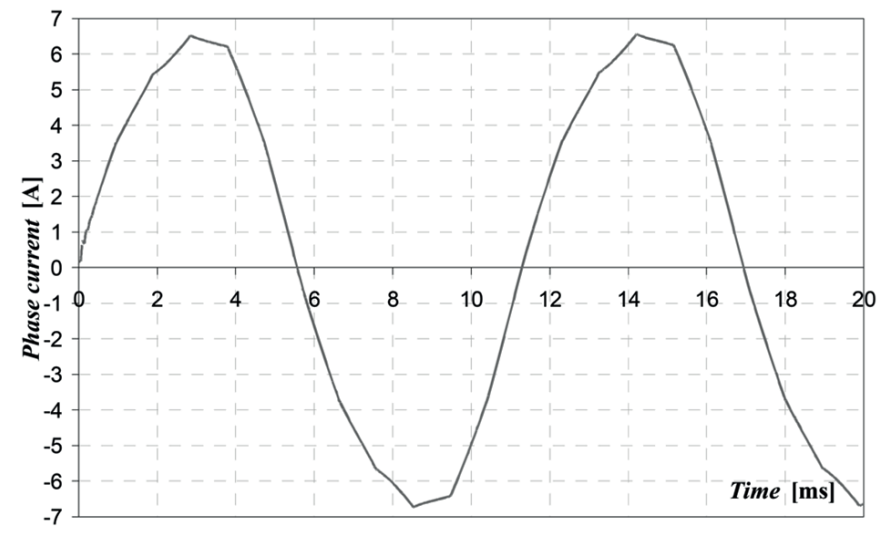

b)

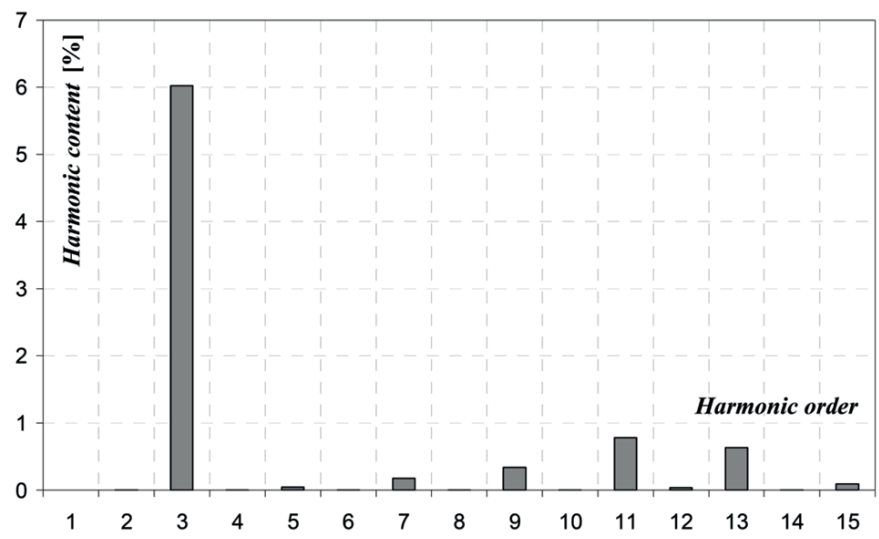

Fig. 8. a) waveform of equivalent current $\left(i_{\mathrm{eq}}\right)$ and b) its harmonic content

have been compared between the star-delta machine and the machine with a classic design. A comparison of the obtained torque waveforms for $i_{\mathrm{eq}}=7 \mathrm{~A}$ and $a=a_{\mathrm{max}}$ is shown in Fig. 9.

Comparing the waveforms, it can be noted that the differences are not significant and no drop-off in performance of

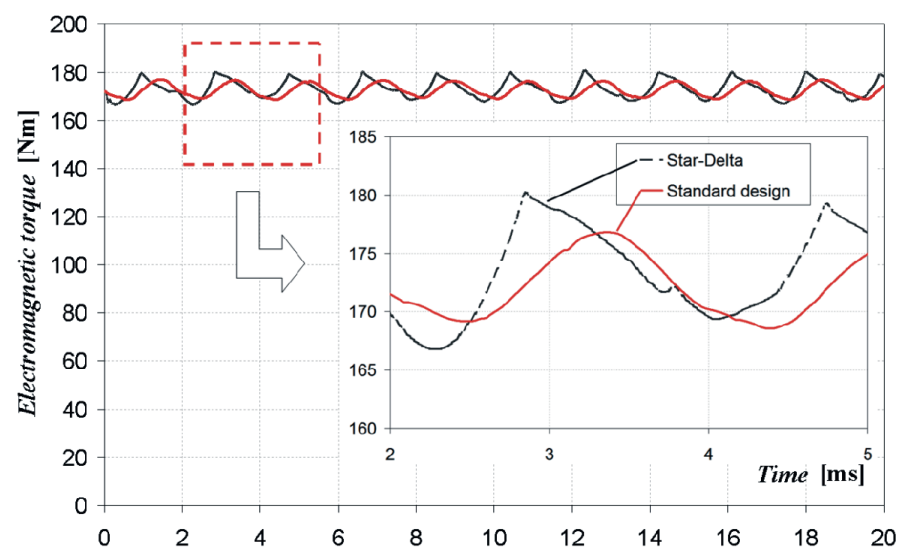

Fig. 9. Electromagnetic torque waveforms at the rated current of the machine with a standard design and of a generator with star-delta winding 
a)

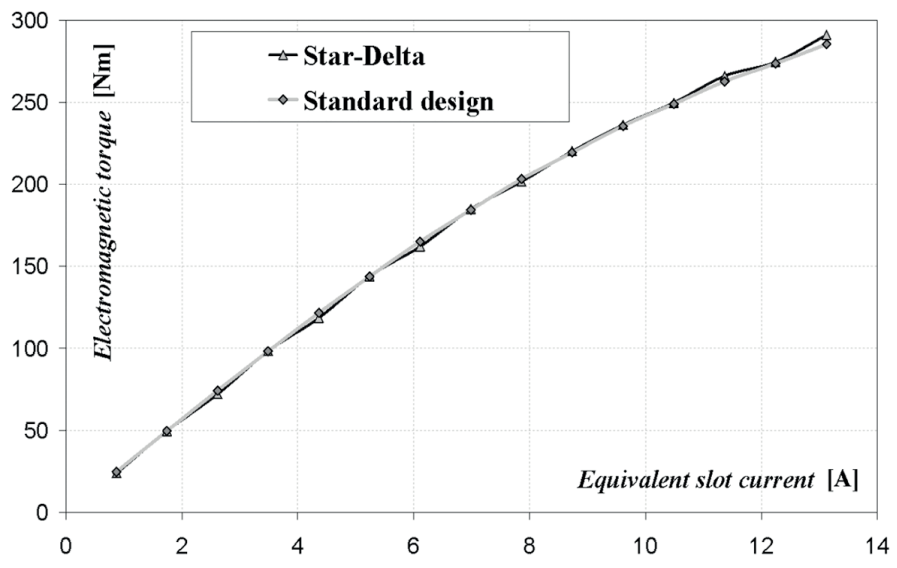

b)

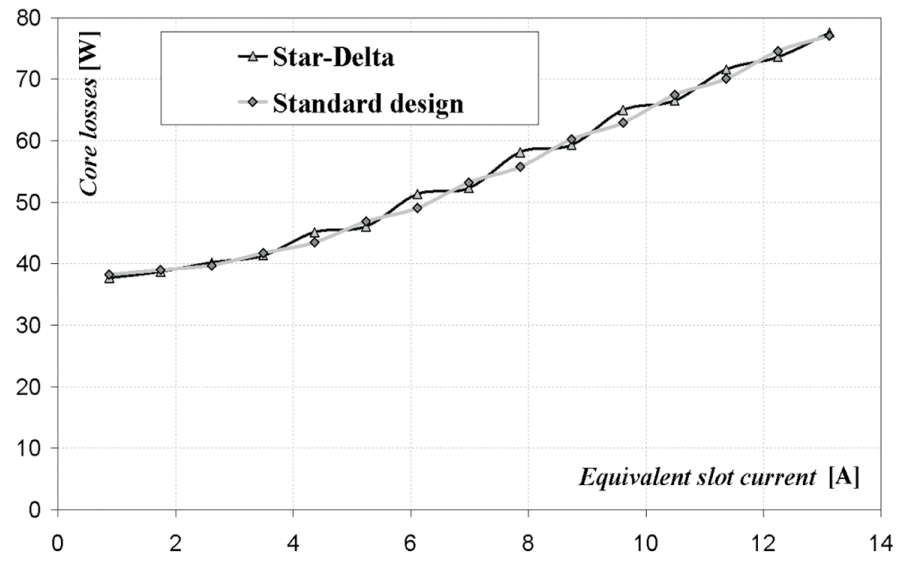

Fig. 10. a) average electromagnetic torque and b) core losses as a function of the equivalent current for machines with a standard design and a generator with star-delta winding

the machine with star-delta winding can be observed. Focusing on the torque ripple factor, it can be stated that the proposed winding design and supply strategy have a marginal impact on the torque ripples (the torque ripple factor equals to $1.74 \%$ for the classic standard design and $2.13 \%$ for the proposed machine with star-delta windings).

In order to compare the torque constants and core losses at the full range of supply currents, the characteristics of the average electromagnetic torque and core losses vs. current have been determined. For each point of characteristics shown in Fig. 10, the $a_{\max }$ has been determined iteratively.

Summarizing the obtained results of the performed finite element analysis, it can be concluded that, when comparing a machine with star-delta winding to a machine with a standard designed magnetic circuit, practically no drop off in performance can be observed. Both machines present the same torque vs. current characteristics while the calculated core losses are on the same level. Looking at the machine design aspect, the increased number of coils in slots in the case of the generator with the star-delta winding will result in a lowered value of the slot fill factor (due to the need of additional insulation between the coils) and a doubled number of terminals/connections between the coils. In general, it will lead to the increase of the cost of the machine. Preliminary studies on material consumption and technological processes, consulted with the producer of electric machines, shows that the increase of cost in relation to the standard design will not be significant (it depends on the power of the machine, however it should not exceed 15\%).

3.2. Model of the power electronics section of the system. For the evaluation of the loss in the power electronics section of the proposed system, a simulation model of this section was built in the OrCAD/PSPICE environement. Models of IGBT IPMs were based on components manufactured by MITSUBISHI ELECTRIC. For the calculation of power loss in these modules, this company supplies software developed by themselves, namely the Melcosim environment [38]. The latest (i.e. 5.3.0) version of this tool was also used in the simulation model studies.

The model of the proposed system consists of the following blocks:

- Replacement model of the generator. This block consisted of a three-winding transformer with a secondary side winding connected in star and delta configurations. The primary side was connected to a 3-phase power source with an output voltage that varied in the range of 80-400 V (i.e. $20-100 \%$ of the rated system's output voltage). The output frequency varied in the range of 10-50 Hz.

- Model of the rectifier. This model was based on the 3-phase bridge rectifier module 26MT120 (25 A/1200 V) from VISHAY [39].

- Model of the current modulator. The CM is the system operating in a closed feedback loop, and thus, its stability can be an issue. Nevertheless, neither this aspect of the $\mathrm{CM}$ operation nor the details of its arrangement are the subject for consideration of the present work. The main elements being used in this model were: the IGBT-based H-bridge, coil, and pulse transformer. The coil forms the passive filter of the PWM carrier components in the modulator current. The model of the semiconductor device was based on the IPM/IGBT type PM25CL1A120 $(25 \mathrm{~A} / 1200 \mathrm{~V})$ [40]. The models of the pulse transformer and coil were based on real devices used in power electronics laboratory experiments [34].

- The L-block was the resistor. The value of its resistance varied, so as to maintain the output current at a constant and equal value to that of the nominal value.

Other basic characteristics and parameters of the MNS were as follows: rated frequency of the generator output voltage $f_{\mathrm{G}, \mathrm{n}}=50 \mathrm{~Hz}, U_{\mathrm{OUT}, \mathrm{n}}=535 \mathrm{~V}, I_{\mathrm{OUT}}=I_{\mathrm{OUT}, \mathrm{n}}=10 \mathrm{~A}$, the reference signal for $\mathrm{CM}\left(i_{\mathrm{CM}, \mathrm{n}}\right)$ was given by $(5), N=1$, $L_{\mathrm{CM}}=350-450 \mu \mathrm{H}$ (the inductance of the coil depends on the value of the coil current), and PWM carrier frequency $f_{\mathrm{c}}=10 \mathrm{kHz}$. 
The selected waveforms in the simulation model for the rated system's output power are shown in Fig. 11.

The shapes of the modulator current and the reference signal almost coincide, however in transient states, these signals differ slightly from each other. This occurrence is shown in the frame in Fig. 11, which also contains the magnified portion of the

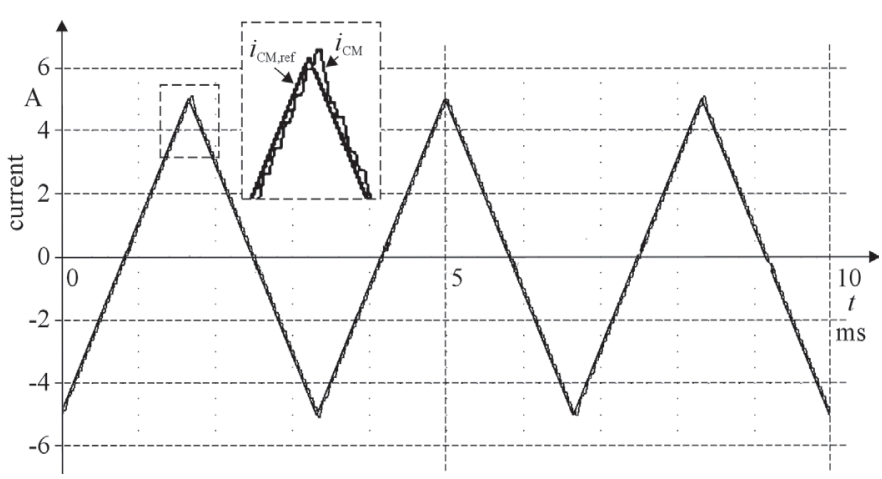

Fig. 11. Waveforms of the reference signal $\left(i_{\mathrm{CM}}\right.$, ref $)$ for the modulator and the modulator output current $\left(i_{\mathrm{CM}}\right)$

drawing. The difference between both currents is the result of the nonlinearity of the magnetic circuit, the limited frequency response of the current modulator, as well as the limited gain of the current regulator in the CM. In Fig. 12, a sample of the reference phase current $\left(i_{\mathrm{X}, \text { ref }}\right)$ as well as the phase current as the result of the simulation model operation $\left(i_{\mathrm{X}}\right)$ in the star winding are shown.

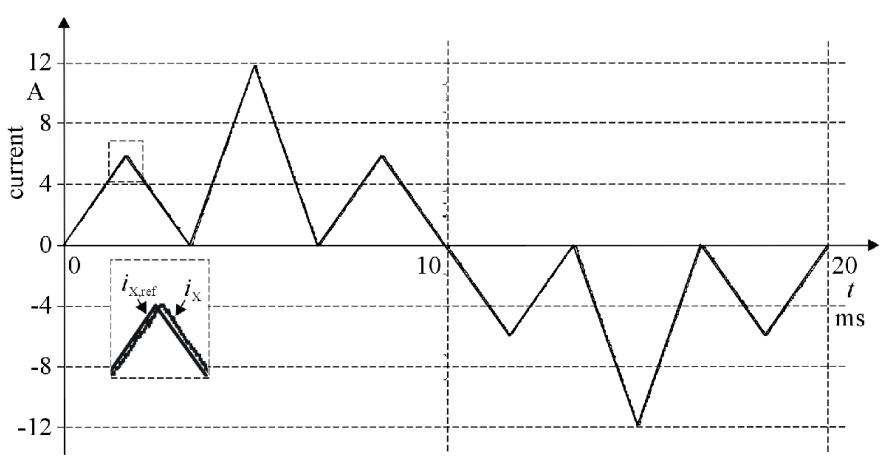

Fig. 12. Exemplary waveforms of the reference (phase) current and phase current as a result of the simulation model operation in the star winding

The adequate and reliable criterion of the generator current quality (for given phase: A, B, or C) can be the control error $\varepsilon$ defined by the equation:

$$
\varepsilon=\sqrt{\frac{\left|i_{\mathrm{X}, \mathrm{ref}}(t)-i_{\mathrm{X}}(t)\right|^{2}}{\overline{\left|i_{\mathrm{X}, \mathrm{ref}}(t)\right|^{2}}}} 100 \%, \mathrm{X}: \mathrm{A}, \mathrm{B}, \mathrm{C} .
$$

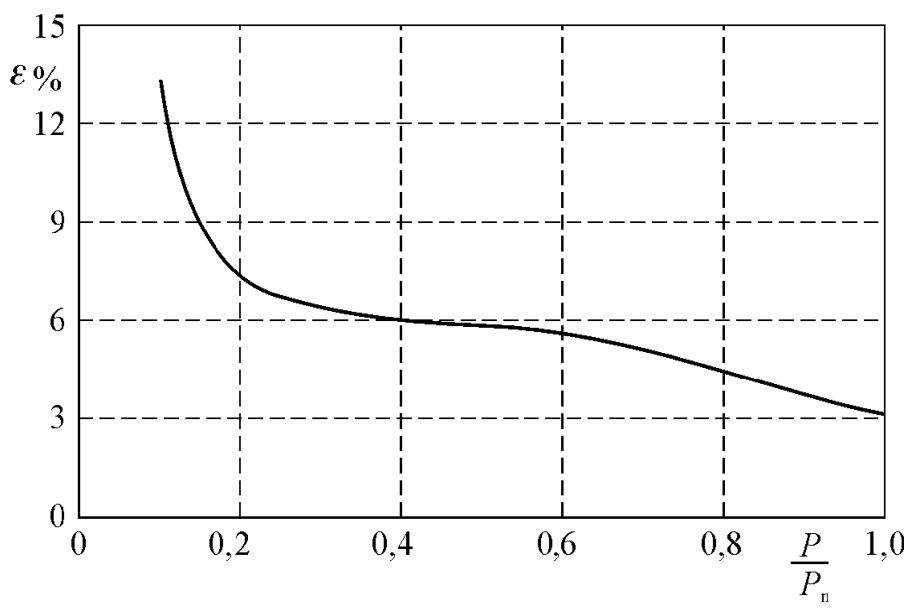

Fig. 13. Curve of control error vs. relative system output power

Calculated by means of a simulation model curve, a control error vs. system output power graph is shown in Fig. 13.

In the analyzed range of output power change, this error does not exceed $7 \%$. It is obvious that the value of the control error affects the value of power loss in the generator, therefore it should be minimized.

In the case of the MSS, the generator was replaced by a 3-phase transformer connected in the star configuration. The active rectifier in the MSS also used the PM25CL1A120 type IPM. The generator phase currents were synchronized with suitable phase voltages, and thus, $P F \cong 1(0.99)$ was obtained. The rated voltage in the DC circuit was equal to $600 \mathrm{~V}$ and the rated output current was $9 \mathrm{~A}$. Other MSS parameters and simulation conditions were the same as in the case of the MNS. In Fig. 14, the curves of the simulation model efficiency $\left(\eta_{\mathrm{E}}\right)$ for both the MNS and the MSS vs. the relative system output power are shown.

The value of efficiency of the proposed system is clearly higher than that of a standard model - by 1.1-2.9\%, depending on the output power. In the case of the MNS, the efficiency simply grows with a decrease in output power. This is an important advantage of the proposed system, because it is very rare for the RES to operate in nominal conditions.

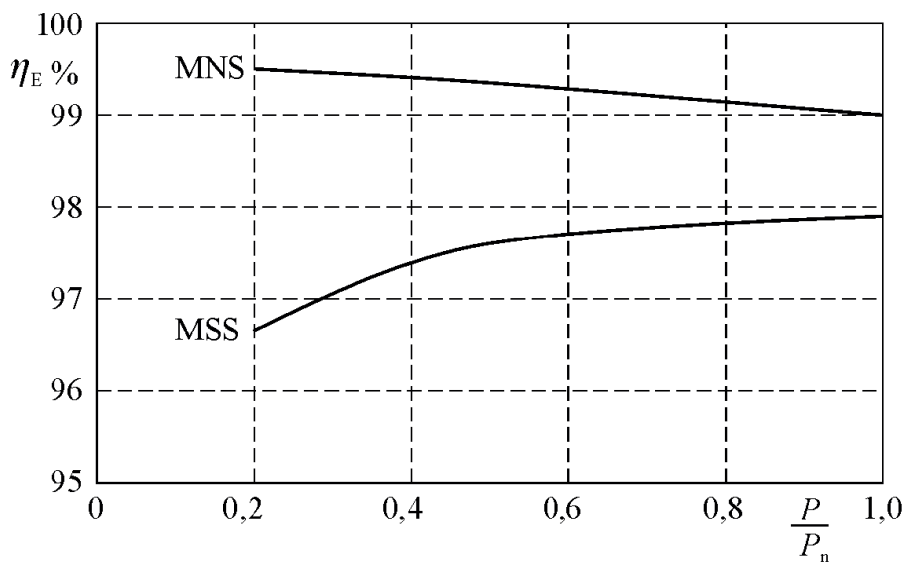

Fig. 14. Efficiency of MNS and MSS vs. relative system output power 


\section{Laboratory tests}

The aim of the test was the validation of theoretical assumptions and research results of the rectifier simulation model - mainly in relation to the quality of the modulator current. The control module in the laboratory model was the ALS-G3-1369 [41] DSP evaluation board with Analog Devices ADSP-21369 SHARC ${ }^{\circledR}$ DSP. In the execution block the P3-5-550MFE LABINVERTER [41] was utilized. Both development systems are dedicated for industrial measurements and power electronics applications. Laboratory tests of the model have been carried out for the current modulator magnitude being in the range of $20-100 \%$ of the nominal one. The criterion of the modulator current quality was also the control error $\left(\varepsilon_{\mathrm{CM}}\right)$ defined as:

$$
\varepsilon_{\mathrm{CM}}=\sqrt{\frac{\overline{\left|i_{\mathrm{err}}(t)\right|^{2}}}{\overline{\left|i_{\mathrm{CM}, \mathrm{ref}}(t)\right|^{2}}}} 100 \%,
$$

where: $i_{\mathrm{err}}(t)=i_{\mathrm{CM} \text {, ref }}(t)-i_{\mathrm{CM}}(t)$.

Registered values of the control error were in the range of $4.5-11.0 \%$ (higher values apply to a smaller modulator current). The selected waveforms in the laboratory model are shown in Fig. 15.

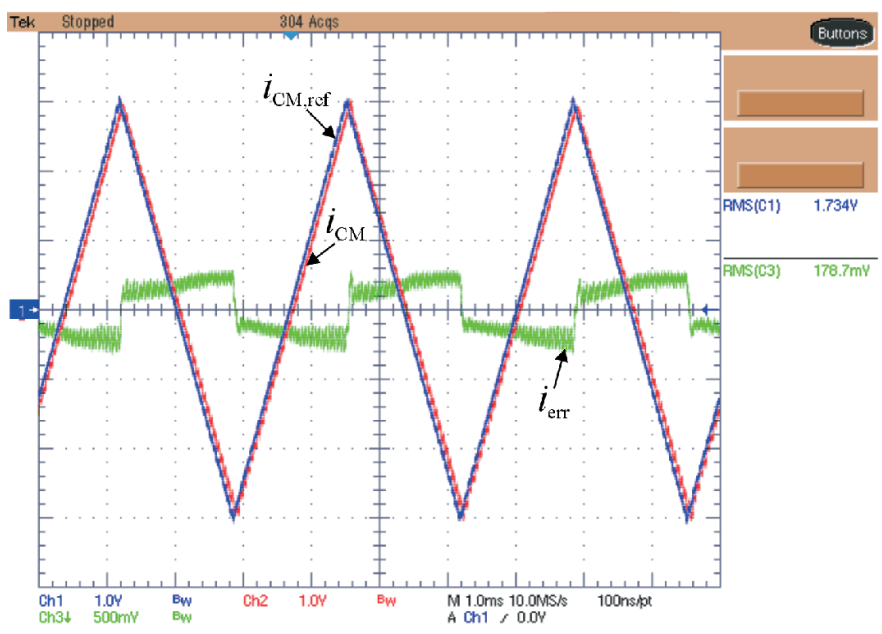

Fig. 15. Waveforms in the laboratory model of the current modulator: reference current (blue line), modulator current (red line), and error signal (green line). The magnitude of the reference signal is equal to $60 \%$ of the rated one and frequency is equal to $300 \mathrm{~Hz}$

Relatively high (comparing to the simulation model - Fig. 13) control error values are caused mainly by errors (e.g. offsets, non-linearity) of real current transducers implemented in the development system, for which the rated total accuracy is equal to $0.7 \%$.

\section{Conclusions}

The results of research of the simulation models, as well as the preliminary laboratory tests, confirm the theoretical assumptions adopted in the course of the study on the energy conversion system based on the proposed generator. The power loss in the "iron" of the generator with modulated magnetic flux is comparable to the power loss in a standard design of a 3-phase PMSG. Dynamic power loss, associated with hard switching power electronics devices (typically IGBT), is negligible, whereas the system's static power loss decreases with a decrease of the system's output power. Therefore, compared to the popular power conversion system that uses a PMSG in cooperation with a full-power active rectifier, it is showed that the characteristics of the proposed solution allow for an overall increase in its resultant efficiency (effectiveness). Given the solutions in relation to other systems for RES, the following of its features are also expected: an increase in the reliability of the operation, a reduction of the maintenance costs, and the ability to more easily meet the EMC requirements. The studies have also indicated that the cost of making the system should be lower when compared to most other solutions for RES. Moreover, it is theoretically possible to further minimize the core losses of the generator by modifying (4) to such a form that allows achieving the sinusoidal shape of the magnetic flux instead of the $m m f$. Improvement of the presented solutions will be the scope of further work.

It should be noted that the proposed system is also suitable for co-operation with water turbines, as well as other turbines (not necessarily related to RES), without practically any significant changes to its basic power section.

\section{REFERENCES}

[1] Global Wind Energy Council, http://www.gwec.net/publications/ global-wind-report-2.

[2] L.H. Hansen, L. Helle, F. Blaabjerg, E. Ritchie, S. Munk-Nielsen, H. Binder, P. Sorensen, and B. Bak-Jensen, Conceptual Survey of Generators and Power Electronics for Wind Turbines, Riso National Laboratory, Roskilde, 2001.

[3] J. Soens, Impact of Wind Energy in a Future Power Grid, Ph.D. Dissertation, Department of Electrical Engineering (ESAT), KU Leuven, Belgium, 2005.

[4] H. Polinder, D.J. Bang, H. Li, and Z. Chen, Concept Report on Generator Topologies, Mechanical and Electromagnetic Optimization, Deliverable No.: D 1B2.b.1, 2007.

[5] P.W. Carlin, A.S. Laxson, and E.B. Muljadi, The History and State of the Art of Variable-Speed Wind Turbine Technology, Technical report NREL/TP-500-2867, National Renewal Energy Laboratory, Golden, CO, USA, 2001.

[6] Z. Chen, "Issues of connecting wind farms into power systems", Proceedings of Transission and Distribution Conference and Exhibition: Asia and Pacific, 2005 IEEE/PES, (2005).

[7] V. Akhmatov, Induction Generators for Wind Power, Multi-Science, Brentwood, 2007.

[8] D.S. Henderson, "Synchronous or induction generators? - the choice for small scale generation", International Conference on Opportunities and Advances in International Electric Power Generation, 146-149 (1996). 
[9] H. Muller, M. Poller, A. Basteck, M. Tilscher, and J. Pfister, "Grid compatibility of variable speed wind turbines with directly coupled synchronous generator and hydro-dynamically controlled gearbox", $6^{\text {th }}$ International Workshop on Large-Scale Integration of Wind Power and Transmission Networks for Offshore Wind Farms, (2006).

[10] M.T. Ameli, S. Moslehpour, and A. Mirzaie, "Feasibility study for replacing asynchronous generators with synchronous generators in wind farm power stations", Proc. 2008 IAJC-IJME International Conference, Paper 129 (2008).

[11] N. Goudarzi, Aerodynamic and Electromagnetic Modeling and Analysis of a Variable Torque Generator for Wind Turbine Applications, MA Thesis, Department of Mechanical Engineering, University of Maryland, Baltimore, MD, USA, 2011.

[12] F. Wang, J. Bai, Q. Hou, and J. Pan, "Design features of low speed permanent magnet generator direct driven by wind turbine", Proc. $8^{\text {th }}$ International Conference on Electrical Machines and Systems, ICEMS 2005 2, (2005).

[13] G. Bywaters, V. John, J. Lynch, P. Mattila, G. Nortor, J. Stowell, M. Salata, O. Labath, A. Chertok, and D. Hablanian, Northern Power Systems Windpact Drive Train Alternative Design Study Report, Subcontractor report NREL/SR-500-35524, National Renewable Energy Laboratory, Golden, CO, USA, 2004.

[14] A. Grauers, Design of Direct-Driven Permanent-Magnet Generators for Wind Turbines, Ph.D. Dissertation, Chalmers University of Technology, Göteborg, Sweden, 1996.

[15] M. Dubois, Optimized Permanent Magnet Generator Topologies for Direct Drive Wind Turbines, Ph.D. Dissertation, Delft University of Technology, Delft, Netherlands, 2004.

[16] P. Lampola, Directly Driven, Low-Speed Permanent-Magnet Generators for Wind Power Applications, Ph.D. Dissertation, Helsinki University of Technology, Helsinki, Finland, 2000.

[17] R. Poore and T. Lettenmaier, Alternative Design Study Report: Windpact Advanced Wind Turbine Drive Train Designs Study, Subcontractor report NREL/SR-500-33196, National Renewable Energy Laboratory, Golden, CO, USA, 2003.

[18] H. Polinder, F.F.A. Pijl, G.J. De Vilder, and P. Tavner, "Comparison of direct-drive and geared generator concepts for wind turbine", IEEE Transactions on Energy Conversion 21, 725-733 (2006).

[19] R.S. Semken, M. Polikarpova, P. Roytta, J. Alexandrova, J. Pyrhonen, J. Nerg, A. Mikkola, and J. Backman "Direct-drive permanent magnet generators for high-power wind turbines: benefits and limiting factors", IET Renewable Power Generation 6 (1), 1-8 (2012).

[20] P.W. Eckels and G. Snitchler, "5 MW high temperature superconductor ship propulsion motor design and test results", Naval Engineers Journal 117 (4), 31-36 (2004).

[21] B. Badrzadeh, "Qualitative performance assessment of semiconductor switching device, converter and generator candidates for $10 \mathrm{MW}$ offshore wind turbine generators", Wind Energy 14 (3), 425-448 (2011).

[22] A. Gupta, D.K. Jain, and S. Dahiya, "Some investigations on recent advances in wind energy conversion systems", IPCSIT 28, 47-52 (2012).
[23] G.M. Pellergrino, F. Villata, P. Guglielmi, and A. Vagati, "Design of direct-drive, low-speed PM machines", Industry Applications Conference, $38^{\text {th }}$ IAS Annual Meeting 2, 1421-1428 (2003).

[24] K.W.E. Cheng, J.K. Lin, Y.J. Bao, and X.D. Xue, "Review of the wind energy generating system", $8^{\text {th }}$ International Conference APSCOM, (2009).

[25] R. Schiferl, "High-temperature superconducting synchronous motors: economic issues for industrial applications", IEEE Transactions on Industry Applications 44 (5), 1376-1384 (2008).

[26] C. Lewis and J. Muller, "A direct drive wind turbine HTS generator”, 2007 IEEE Power Engineering Society General Meeting, (2007).

[27] S.S. Kalsi, K. Weeber, H. Takesue, C. Lewis, H.W. Neumueller, and R.D. Blaugher, "Development status of rotating machines employing superconducting field winding", Proc. IEEE 92 (10), 1688-1704 (2004).

[28] S.S. Kalsi, "Development status of superconducting rotating machines", 2002 IEEE Power Engineering Society Winter Meeting 1, 401-403 (2002).

[29] J.R. Hull and M. Murakami, "Applications of bulk high temperature superconductors", Proc. IEEE 92 (10), 1705-1718 (2004).

[30] P.J. Masson and C.A. Luongo, "High power density superconducting motor for all-electric aircraft propulsion", IEEE Transactions on Applied Superconductivity 15 (2), 2226-2229 (2005).

[31] M.J. Superczynski and D.J. Waltman, "Homopolar motor with high temperature superconductor field windings", IEEE Transactions on Applied Superconductivity 7 (2), 513-518 (1997).

[32] R. Strzelecki and H. Supronowicz, The Power Factor of AC Circuits and Correction Method, pp. 120-135, OWPW, Warszawa, 2000, [in Polish].

[33] D. Schulz, "Improved Grid Integration of Wind Energy Systems", Bull. Pol. Ac.: Tech. 57 (4), 311-315 (2009).

[34] M. Krystkowiak and M. Gwóźdź, "Simulation and experimental models of 3-phase diode rectifier with current modulation in DC circuit", Przeglad Elektrotechniczny R87 (1), 75-79 (2011).

[35] A. Pantea, A. Yazidi, F. Betin, G.A. Capolino, and V. Lanfranchi, "Six-phase axial flux permanent magnet generator model: simulation and experimental validation", 2016 IEEE 25th International Symposium on Industrial Electronics, 192-197 (2016).

[36] P. Stawczyk and S Karys "Three-phase one-branch controlled bridge rectifier for permanent magnet $\mathrm{AC}$ synchronous generator", 2016 10th International Conference on Compatibility, Power Electronics and Power Engineering (CPE-POWERENG), 450-454 (2016).

[37] Windtec Solutions, Seatitan $10 \mathrm{MW}$, http://www.amsc.com/documents/seatitan-10-mw-wind-turbine-data-sheet.

[38] MITSUBISHI ELECTRIC, Power Module Loss Simulator, http:// www.mitsubishielectric.com/semiconductors/dm/u_als_form.html.

[39] http://www.vishay.com/product?docid $=93565$.

[40] http://www.mitsubishielectric.com/semiconductors/products/powermod/intelligentpmod/index.html.

[41] http://analog.alfine.pl/oferta/produkty-alfine/systemy-uruchomieniowe. 